\title{
Rastreando os direcionadores da performance organizacional: uma proposta metodológica
}

\author{
Bruno Henrique Rocha Fernandes *
}

\begin{abstract}
Resumo
Este artigo tem por objetivo propor uma metodologia para rastrear a seqüência de causalidade entre direcionadores e indicadores de performance dentro de um sistema de avaliação da performance organizacional. A metodologia propõe 0 levantamento das principais variáveis relacionadas ao desempenho da organização, a simplificação dos dados mediante técnicas de análise fatorial e a aplicação de análises de regressão e de modelagem de equações estruturais para testar modelos causais de maior poder explicativo. A título de ilustração, a metodologia é aplicada a uma empresa composta de unidades de negócio e gerenciada a partir de um modelo de mensuração de performance. No estudo, constatou-se que algumas variáveis supostamente causadoras da performance, como a competência dos funcionários, aparentemente não causavam nenhum efeito. Outras, como a satisfação dos empregados, mostraram-se relacionadas à performance, com efeito direto sobre algumas dimensões (como performance operacional) e indireto sobre outras (como satisfação de clientes e desempenho financeiro).
\end{abstract}

Palavras-chave: mensuração de desempenho; direcionadores do desempenho; competências.

\begin{abstract}
This paper proposes a methodology to study the linkage between organizational performance drivers like internal resouces and competences, and organizational performance through its multiple perspectives like internal performance measures and its overall ability to meet financial and customer targets. Firstly the methodology suggests the exam of the main variables related to firm performance and the design of casual maps. Next data are collected according to that design and simplified using factorial analysis. Then, statistical techniques like regression analysis and structural equation modelling are employed to investigate relationship among variables to confirm or not the assumed linkages. As an example, the methodology is employed in a firm with a hundred business units, all monitored with similar performance indicator measurement. In the example, some drivers like human competency showed no association with organizational performance, whereas drivers like tangibles resource density and employee satisfaction seemed to affected internal process productivity, customer satisfaction and financial targets.
\end{abstract}

Keywords: performance measurement; performance drivers; competences.

\section{Introdução}

Kaplan e Norton (1992), por meio de seu balanced scorecard (BSC), popularizaram a idéia de se olhar para a performance organizacional além de seus resultados financeiros. De forma geral, chamaram a atenção para o fato de que o desempenho financeiro de uma organização é consequiência de decisões tomadas anteriormente, que estimulem a competência e a motivação da força de trabalho, desenvolvam uma infra-estrutura adequada e impliquem processos internos alinhados, resultando em satisfação e lealdade por parte de seus clientes.

Entretanto, tais autores não foram pioneiros nessa idéia. Já na década de 1950, a literatura e a prática da administração francesa começaram a trabalhar com a ferramenta do Tableau de Bord, um sistema que objetivava aperfeiçoar o processo produtivo, propiciando melhor entendimento das relações de causa-e-efeito

\footnotetext{
* Titulação Professor Professor e coordenador do mestrado do Centro Universitário Positivo (UnicenP-Curitiba/PR). Doutor em Administração de pela Faculdade de Economia, Administração e Contabilidade da Universidade de São Paulo (FEA-USP/SP). E-mail: bruno@ unicenp.br.

Artigo recebido em julho de 2004 e aprovado em outubro de 2004.
} 
dentro da empresa (EPSTEIN e MANZONI, 1998, p.191) e que com o tempo, teve sua aplicação estendida a outros níveis organizacionais.

Apesar do pioneirismo, o Tableau de Bord ficou restrito às fronteiras da França. Além do mais, como Epstein e Manzoni (1998, p.197) argumentam, o modelo ainda possuía algumas limitações, como certo viés financeiro privilegiando essas medidas em detrimento das não-financeiras - e a coleta e disseminação de medidas de desempenho correntes, em vez de partir de uma visão estratégica para definir os indicadores relevantes.

O BSC de Kaplan e Norton (1992) parece encaminhar tais questões, ao estabelecer quatro perspectivas da performance organizacional a serem monitoradas de forma balanceada: a financeira, a dos clientes, dos processos internos e a da aprendizagem e crescimento. Além da proposição das quatro perspectivas para monitoramento e controle, Kaplan e Norton (1996, p.30-31) sugerem a existência de relações de causalidade entre essas dimensões. Os indicadores financeiros são atingidos à medida que a empresa atende e satisfaz seus clientes; o que, por sua vez, só ocorre se os processos internos estiverem alinhados para alcançar a excelência. Por fim, a excelência nos processos internos é consequiência de pessoas motivadas e competentes, além de sistemas que respondam adequadamente às necessidades organizacionais. Essa ordem de causalidade é expressa nos chamados mapas causais. ${ }^{1}$ A figura 1 apresenta um mapa causal genérico. Todavia, vale destacar que cada organização deverá desenvolver seu mapa específico, segundo as dimensões que julgar mais relevantes.

Figura 1

Mapa causal de um balanced scorecard

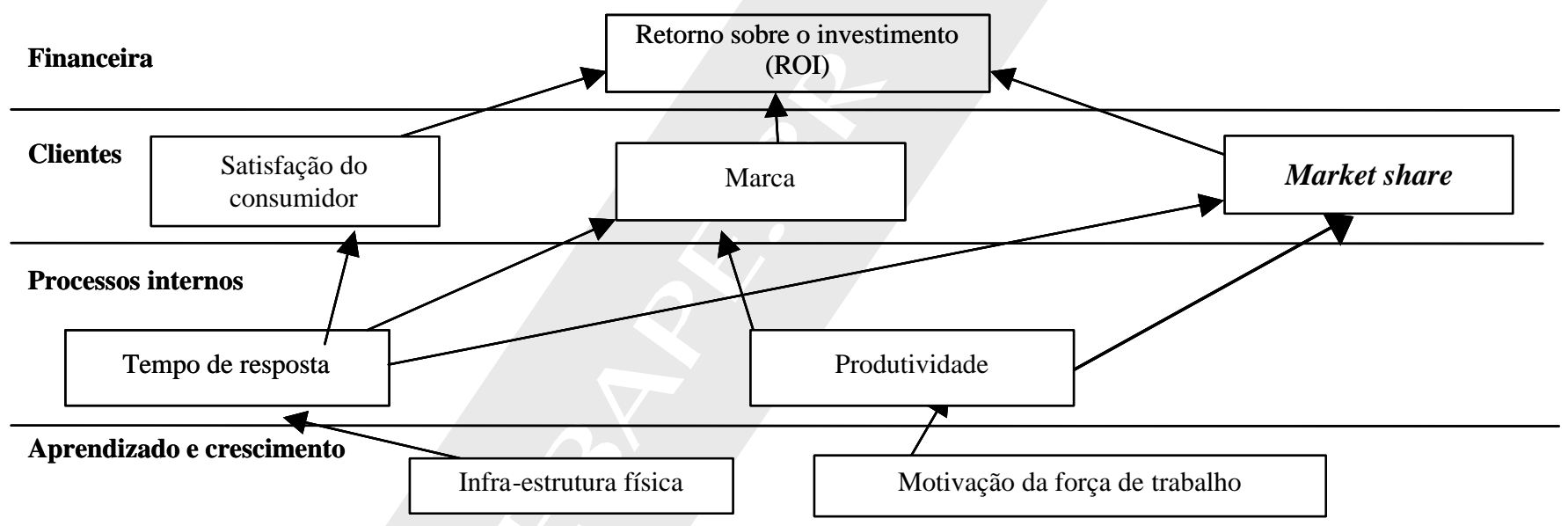

Fonte: autor.

A fim de reforçar a idéia, Kaplan e Norton (1996) propõem um exemplo:

"Se nós aumentarmos o treinamento dos empregados sobre estes produtos, então eles estarão mais conscientes de toda a linha de produto que podem vender; se os empregados estão mais conscientes sobre os produtos, então a efetividade de suas vendas aumentará. Se a efetividade de suas vendas aumenta, então a lucratividade dos produtos que eles vendem irá aumentar" (p.149).

1 A noção de mapa causal não é exclusividade do modelo BSC. Segundo Huff (1990), mapas causais constituem casos particulares da noção de "mapas cognitivos", conceitos e relações que um indivíduo usa para compreender várias situações ou ambientes. Os mapas cognitivos funcionam como mapas que permitem ao indivíduo perceber 0 ambiente numa escala mais ampla que a de percepção imediata. 
Os autores vão mais longe na idéia de causalidade no BSC. Sugerem que "todas as medidas escolhidas para um balanced scorecard deveriam ser um elemento de uma cadeia de relações de causa-e-efeito que comunicam o significado da estratégia de uma unidade de negócios para a organização" (p.149). ${ }^{2}$

Apesar dessa clareza de propósito, na prática, tais mapas causais são construídos de maneira mais ou menos intuitiva. Ao formular e propor um determinado mapa para suas organizações, os gestores explicitam suas crenças sobre relações de causalidade que não necessariamente são verdadeiras. Contudo, ainda são relativamente poucos os estudos que examinam sobre bases estatísticas resultados da implantação de um sistema de gestão de performance como o BSC, a fim de confirmar ou não supostas relações de causalidade.

O objetivo deste artigo é propor uma metodologia para averiguar relações de causalidade na implantação de um sistema de mensuração de performance; e, nessa medida, vale destacar que a metodologia proposta não se volta apenas para o BSC. Este artigo propõe a metodologia, baseada no uso de modelos de equações estruturais ( $s$ tructural equation modeling - SEM), ao mesmo tempo em que a submete a teste em uma circunstância concreta de uma determinada organização, apresentando alguns dos resultados obtidos.

\section{Fundamentação teórica}

Diversos pesquisadores têm se esforçado para rastrear as causas de uma performance organizacional diferenciada. Uma linha de trabalho é representada por autores da área de recursos humanos, que procuram demonstrar que, no limite, toda vantagem competitiva deriva do modo pelo qual as empresas gerenciam suas pessoas. Essa linha de reflexão está bem sintetizada numa edição especial de 1996 da revista Academy of Management Journal, sobre estudos relacionando práticas de RH à performance (Special Research Forum: Human Resource Management and Organizational Performance). Num artigo ao mesmo tempo de revisão de literatura e de apresentação do volume, Becker e Gerhart (1996) retomam os princípios da "visão da empresa baseada em recursos" (VBR) de Penrose (1959), para explicar seu raciocínio:

"de acordo com a VBR, as empresas podem desenvolver vantagem competitiva sustentável, somente criando valor de uma maneira que seja escassa e difícil para os concorrentes imitarem. Embora as fontes tradicionais de vantagem competitiva como recursos naturais, tecnologia, economias de escala, e assim por diante, gerem valor, a VBR sugere que tais recursos são cada vez mais fáceis de imitar, especialmente, quando comparados com estruturas sociais complexas como o sistema de trabalho. Se é assim, então as estratégias de recursos humanos podem ser especialmente importantes como fonte de vantagem competitiva sustentável” (p.781-782).

Entretanto, ao considerarem os papers apresentados no volume e outras pesquisas na área, constatam algumas limitações. Uma delas é a de que com as pesquisas publicadas até então, "o melhor que podemos fazer é olhar o grupo de estudos e dizer que o RH está relacionado à performance no nível da empresa ou da fábrica” (p.793), mas sem poder concluir nada sobre como os processos de RH levam à performance. Em geral, estudos empíricos na área têm se apoiado em modelos de regressão, com adoção gradual de variáveis e análise do RH, ou em análises de interação, como MANOVA ${ }^{3}$. Porém, modelos estruturais continuavam incomuns nesse campo de pesquisa. Nesse sentido, Becker e Gerhart (1996) sugerem o uso do BSC como um caminho para se aprofundar as relações causais entre direcionadores, como práticas de $\mathrm{RH}$, e outras dimensões da performance.

Em outra revisão, mais recente, Rocha-Fernandes (2004) constatou que continuam atuais as observações de Becker e Gerhart (1996) referentes à escassez de modelos estruturais em estudos relativos à performance.

2 Ao construir mapas causais, dirigentes optam por determinados fenômenos aparentemente concatenados. Entretanto, será o monitoramento desses fenômenos que permitirá detectar relações de fato. Dessa forma, definir, monitorar e testar suposições através de mapas causais constitui um meio para gerar aprendizado organizacional.

3 Multivariate Analysis of Variance and Covariance (análise multivariada da variância e da covariância) é uma técnica estatística que usada para explorar simultaneamente a relação entre várias categorias de variáveis dependentes e duas ou mais variáveis dependentes métricas (HAIR, 1998, p. 15). 
Examinando estudos no campo dos "sistemas de trabalho de alta performance" (HPWS), ${ }^{4}$ pesquisas alinhadas ao "espelho da satisfação" (HESKETT, SASSER e SCHLESINGER, 1997) e também na área de mensuração de performance, o autor identificou três trabalhos abrangendo modelos estruturais: a pesquisa de Rucci, Kim e Quinn (1998), descrevendo a experiência de implantação do BSC na Sears, cadeia de varejo americana; a survey de Barber, Hayday e Bevan (1999), voltada para empresas de varejo britânicas; e a análise de Neely e Najjar (2003), examinando o impacto da satisfação do funcionário sobre a satisfação do cliente e da rentabilidade na British Airways e em uma empresa de serviços denominada X. Em todos os casos, as pesquisas apresentaram escopo limitado. Por considerarem um único direcionador da performance, dentro da perspectiva de aprendizado (em geral, satisfação dos funcionários ou HPWS), ou por enfatizarem uma ou outra dimensão da performance (satisfação dos clientes ou rentabilidade), nenhum dos estudos abrangeu indicadores dentro de "processos internos". Nesse sentido, observa-se uma lacuna em termos de estudos baseados em modelos de equações estruturais que abarquem outros direcionadores ou recursos e que considerem indicadores de performance em todas as perspectivas do BSC, simultaneamente.

\section{Metodologia}

Tendo em vista essa lacuna, foi elaborada uma pesquisa com os seguintes procedimentos:

- identificar uma empresa e/ou setor com unidades comparáveis, em número suficiente para tratamento estatístico e em que se pudesse medir recursos e graus de performance (usando indicadores comuns);

- definir recursos ou direcionadores de performance;

- definir indicadores de performance relevantes, de todas as perspectivas organizacionais do BSC;

- estabelecer ligações entre direcionadores e indicadores de performance, por meio de mapas causais;

- aplicar técnicas de análise fatorial, de forma a simplificar os dados;

- conduzir análises de regressão para verificar as correlações entre recursos e indicadores de performance, bem como de indicadores entre si;

- aplicar técnicas de modelagem de equações estruturais (structural equation modeling) para ajustar o mapa causal com melhor poder explicativo do modelo.

\section{A situação em estudo}

\section{Identificação da empresa}

Para o estudo, foi escolhida uma empresa do setor de saneamento, a Sanepar - Companhia Paranaense de Saneamento. Criada em 1963 para o tratamento de água e esgoto no estado do Paraná, em 2002 - ano a que se referem os dados coletados para a pesquisa -, a empresa faturou cerca de $\mathrm{R} \$ 1$ bilhão, empregando 4.000 funcionários diretos.

Desde 1997, sua estrutura organizacional consiste de dois níveis: uma holding, no nível corporativo, e unidades de negócio, (UNs) no nível operacional. O nível corporativo é responsável por decisões centralizadas, como o processo de investimento, planejamento de longo prazo e P\&D. As unidades de negócio são de dois tipos: unidades de serviço (US), cujo papel é oferecer serviços no mercado interno para outras UNs, e unidades de receita (UR), que lidam com clientes externos. As USs incluem recursos humanos, manutenção, contabilidade, engenharia etc., obtendo sua receita por um sistema de transferência de preços internos. Por ocasião da pesquisa, a empresa possuía 93 UNs, sendo 38 delas URs.

\footnotetext{
4 Sistemas de trabalho de alta performance ou high performance work systems (HPWS) é a expressão que a literatura especializada tem usado para definir (vagamente) uma série de inovações no ambiente de trabalho, como equipes semi-autônomas, sistemas sociotécnicos, sistemas de planejamento participativos, desenhos inovadores de plantas, remuneração elevada, uso intensivo de práticas de RH etc. (FARIAS e VARMA, 1998).
} 
O sistema de gestão é inspirado no BSC, embora a empresa não siga rigorosamente o modelo. No início do ciclo de planejamento anual, a UN detalha suas metas de acordo com o planejamento estratégico central. Para cada perspectiva - financeira, clientes, processos internos e aprendizado - existem indicadores de performance que devem ser atingidos como metas. Durante o processo de definição de metas, os gestores das UNs negociam com unidades fornecedoras, clientes e pares para chegarem a números factíveis; depois, negociam com o nível corporativo. Os resultados da discussão são estabelecidos como metas a serem cumpridas pela UN no exercício seguinte. Parte da remuneração variável está condicionada ao cumprimento dessas metas. Quanto ao sistema de gestão, este é monitorado pelo software SGS, que armazena todos os indicadores das UNs. Em 2002 esse software foi premiado pela Microsoft como a melhor "Solução em Business Intelligence na América Latina" (SANARE, 2002, p.3).

Outro elemento importante é o sistema de gestão de pessoas baseado em competências. O sistema desenhado para a Sanepar inspira-se no modelo de Dutra (2001), que parte dos seguintes conceitos: competência - como conhecimentos, habilidades e atitudes (inputs), aplicados dentro de um contexto profissional -, para agregar valor social ao indivíduo e valor econômico à empresa (outputs ou entrega) (FLEURY e FLEURY, 2001); complexidade, que traduz o nível de abstração em que o indivíduo é capaz de realizar seu trabalho; espaço ocupacional, referente ao conjunto de atribuições e responsabilidades de uma pessoa; e eixos de carreira, trajetórias naturais de crescimento profissional para uma pessoa.

O sistema comporta uma etapa de enquadramento das pessoas dentro de um eixo de carreira e num nível de complexidade caracterizado por um conjunto de competências. A partir daí, o profissional é avaliado conforme seu grau de proficiência em cada uma dessas competências, bem como seu atendimento quanto aos requisitos de acesso (inputs). Um resultado da avaliação é um inventário do nível de competência em cada unidade de negócios.

O modelo de competências da Sanepar é monitorado por meio do software Sistema de Competências e Relações com Empregados (SCRE). O software estabelece parâmetros para todos os critérios do modelo. Permite a avaliação on-line dos funcionários e armazena os resultados das avaliações em uma base de dados, com a distribuição de competências de cada um. A partir dessa base, pode ser gerada uma série de relatórios e saídas gráficas.

Possuir um sistema de avaliação de performance, um sistema de gestão de pessoas baseado em competências e uma estrutura organizacional com unidades comparáveis fazem da empresa um campo privilegiado para investigar a relação entre recursos/direcionadores e performance (MILLS e ROCHA-FERNANDES, 2004).

\section{Definição de direcionadores da performance}

Por meio de workshops, foi feito um levantamento de quais recursos seriam estratégicos às URs para alcançarem seus objetivos. Depois, foram observados os sistemas de gestão da empresa, para localizar onde poderiam ser obtidas informações referentes a tais recursos, indiretamente ou por meio de questionários, conforme mostra o quadro 1. 
Quadro 1

Direcionadores/recursos, formas de mensuração e fonte

\begin{tabular}{|c|c|c|c|}
\hline $\begin{array}{l}\text { TIPO DE } \\
\text { RECURSO }\end{array}$ & VARIÁVEIS & MEDIÇÃO & FONTE \\
\hline \multirow{3}{*}{$\begin{array}{l}\text { Recursos } \\
\text { tangíveis }\end{array}$} & Grau de automação da unidade & Direta & Grau de automação (questionário) \\
\hline & $\begin{array}{l}\text { Recursos materiais (infra-estrutura } \\
\text { física administrativa e rede) }\end{array}$ & Indireta & $\begin{array}{l}\text { Valor patrimonial da unidade } \\
\text { (SGS) }\end{array}$ \\
\hline & $\begin{array}{l}\text { Número de funcionários, aquisição } x \\
\text { perda de funcionários, horas extras }\end{array}$ & Direta & $\begin{array}{l}\text { Número de funcionários, } \\
\text { aquisição } x \text { perda de funcionários, } \\
\text { horas extras (SGS) }\end{array}$ \\
\hline \multirow{5}{*}{$\begin{array}{l}\text { Conhecimentos, } \\
\text { habilidades e } \\
\text { experiências }\end{array}$} & $\begin{array}{l}\text { Competência individual do gestor } \\
\text { (orientação para resultado, liderança } \\
\text { etc.) }\end{array}$ & Direta & Competência e entrega (SCRE) \\
\hline & $\begin{array}{l}\text { Competências da equipe (orientação } \\
\text { para resultado, trabalho em equipe } \\
\text { etc.) }\end{array}$ & Direta & Competência e entrega (SCRE) \\
\hline & Satisfação do colaborador & Direta & Satisfação do colaborador (SGS) \\
\hline & Experiência da equipe & Indireta & Competência e entrega (SCRE) \\
\hline & Treinamento da equipe & Aproximada & Treinamento da equipe (SGS) \\
\hline \multirow{3}{*}{$\begin{array}{l}\text { Procedimentos } \\
\text { e sistemas }\end{array}$} & Sistema de monitoramento & Não há & \\
\hline & $\begin{array}{l}\text { Sistema de remuneração } \\
\text { (participação nos resultados) }\end{array}$ & Não há & \\
\hline & $\begin{array}{l}\text { Sistemas de qualidade (ISSO } 9.000 \\
\text { e } 14.000 ; \text { Pares) }\end{array}$ & Não há & \\
\hline \multirow[b]{2}{*}{$\begin{array}{l}\text { Valores e } \\
\text { cultura }\end{array}$} & Orientação para resultado & Indireta & Competência e entrega (SCRE) \\
\hline & $\begin{array}{l}\text { Orientação para o cliente } \\
\text { (interno/externo) }\end{array}$ & Indireta & Competência e entrega (SCRE) \\
\hline \multirow[t]{2}{*}{ Network } & $\begin{array}{l}\text { Grau de articulação/conhecimento } \\
\text { do gestor/equipe da empresa e do } \\
\text { negócio }\end{array}$ & Indireta & Competência e entrega (SCRE) \\
\hline & $\begin{array}{l}\text { Fornecedores de manutenção e } \\
\text { produção da unidade }\end{array}$ & Direta & $\begin{array}{l}\text { Fornecedores de manutenção e } \\
\text { produção da unidade (SGS) }\end{array}$ \\
\hline \multirow{2}{*}{$\begin{array}{l}\text { Recursos } \\
\text { importantes } \\
\text { para mudança }\end{array}$} & Gestor competente & Direta & Competência e entrega (SCRE) \\
\hline & Recursos financeiros & Indireta & $\begin{array}{l}\text { Valor patrimonial da unidade } \\
\text { (SGS) }\end{array}$ \\
\hline
\end{tabular}

Fonte: autor.

\section{Definição dos indicadores de performance relevantes nas perspectivas do BSC}

Dentre o conjunto de indicadores de performance da empresa voltados para URs (cerca de 70), foram escolhidos os constantes no quadro 2, por sua relevância estratégica. 


\section{Quadro 2}

Explicação de alguns indicadores de gestão da empresa

\section{PERSPECTIVA INDICADORES \\ Financeira EBITDA}

\section{EXPLICAÇÃO}

Resultado da unidade antes de juros, impostos, depreciações e amortizações.

Evasão de receitas Percentual da receita operacional não arrecadado no período.

Margem de despesa pessoal Percentual da receita operacional comprometido com despesas de Margem operacional pessoal.

Receita operacional Percentual da receita operacional comprometido com despesas de exploração.

ajustada Soma da receita tarifária com a receita dos serviços para clientes

Clientes

Aumento das ligações
externos (água, esgoto e demais serviços).

de água Número de ligações de água que a unidade efetivamente Aumento das ligações de esgoto acrescentou.

Satisfação dos clientes Número de ligações de esgoto que a unidade efetivamente acrescentou.

Pesquisa de satisfação composta de atributos para avaliar produtos e serviços, no que se refere à operação, manutenção, atendimento e projetos e obras.

Total de reclamações Soma de todas as reclamações classificadas em: reclamações sobre o faturamento; reclamações sobre os serviços prestados; reclamações relativas à operação do sistema (falta de água, água suja etc.).

Nível de atendimento Nível de cobertura com serviços de água

água

Nível de atendimento Nível de cobertura com serviços de esgoto

esgoto

\begin{tabular}{|c|c|c|}
\hline \multirow[t]{7}{*}{$\begin{array}{l}\text { Processos } \\
\text { internos }\end{array}$} & $\begin{array}{l}\text { Número de ligações } \\
\text { de água }\end{array}$ & Quantidade de ligações de água da unidade \\
\hline & $\begin{array}{l}\text { Número de ligações } \\
\text { de esgoto }\end{array}$ & Quantidade de ligações de esgoto da unidade \\
\hline & Produtividade & $\begin{array}{l}\text { Quantidade de ligações de água e esgoto para cada empregado da } \\
\text { unidade }\end{array}$ \\
\hline & Perdas no faturamento & $\begin{array}{l}\text { Relação entre o volume produzido e o faturado. É uma } \\
\text { composição de perdas físicas e não-físicas que, além das } \\
\text { atribuídas a desvios de medição, incorporam volumes utilizados e } \\
\text { não cobrados }\end{array}$ \\
\hline & $\begin{array}{l}\text { Índice de perdas no } \\
\text { sistema distribuidor - } \\
\text { PSD12 }\end{array}$ & $\begin{array}{l}\text { Volume produzido disponibilizado ao volume utilizado. Água } \\
\text { disponibilizada e não utilizada constitui uma parcela não } \\
\text { contabilizada, que incorpora o conjunto de perdas físicas e não- } \\
\text { físicas no subsistema de distribuição }\end{array}$ \\
\hline & Refluxos de esgoto & Número de refluxos ocorridos para cada 1.000 ligações de esgoto \\
\hline & $\begin{array}{l}\text { Reposição de } \\
\text { pavimentos }\end{array}$ & $\begin{array}{l}\text { Percentual de serviços de reposição de pavimentos, com prazo de } \\
\text { execução igual a } 10 \text { dias em relação ao total de serviços de } \\
\text { reposição de pavimentos }\end{array}$ \\
\hline \multirow[t]{2}{*}{ Aprendizagem } & $\begin{array}{l}\text { Treinamento de } \\
\text { funcionário }\end{array}$ & Quantidade de horas/ano \\
\hline & $\begin{array}{l}\text { Satisfação dos } \\
\text { funcionários }\end{array}$ & Pesquisa de clima \\
\hline
\end{tabular}

Fonte: Sanepar.

de água

de esgoto

Relação entre o volume produzido e o faturado. É uma composição de perdas físicas e não-físicas que, além das não cobrados

Indice de perdas no sistema distribuidor contabilizada, que incorpora o conjunto de perdas físicas e nãofísicas no subsistema de distribuição

Refluxos de esgoto Percentual de serviços de reposição de pavimentos, com prazo de reposição de pavimentos

funcionário

funcionários 


\section{Estabelecimento de ligações entre direcionadores e indicadores de performance por meio de mapas causais}

O grupo também concebeu o mapa cognitivo que liga esses recursos a dimensões da performance. A figura 2 mostra os resultados. A metodologia utilizada consistiu em: primeiro, listar as variáveis mais relevantes para a performance de cada perspectiva; segundo, desenhar setas, assinalando que variáveis influenciam quais. Essas variáveis também foram rastreadas nos sistemas de gestão da empresa. Em particular, para as variáveis de performance, foi considerado o quociente entre metas e valores realizados; ou seja, o quanto as unidades realizaram diante da meta a ser cumprida. Nesse caso, só os resultados alcançados dizem pouco, pois há muitos outros fatores atuantes. Por exemplo, características geográficas como relevo da região influenciam significativamente nos resultados. Uma unidade de negócio A, atendendo uma região com grandes desníveis de altitude, teria um alto consumo de energia elétrica para bombear água, o que não ocorreria com uma unidade B, responsável por uma região plana. Nessa situação, se comparadas as unidades, A teria desempenho superior a $\mathrm{B}$ em indicadores como custos e rentabilidade. Isso, porém, não estaria relacionado à competência, mas a fatores geográficos.

Figura 2

Mapa cognitivo causal do grupo

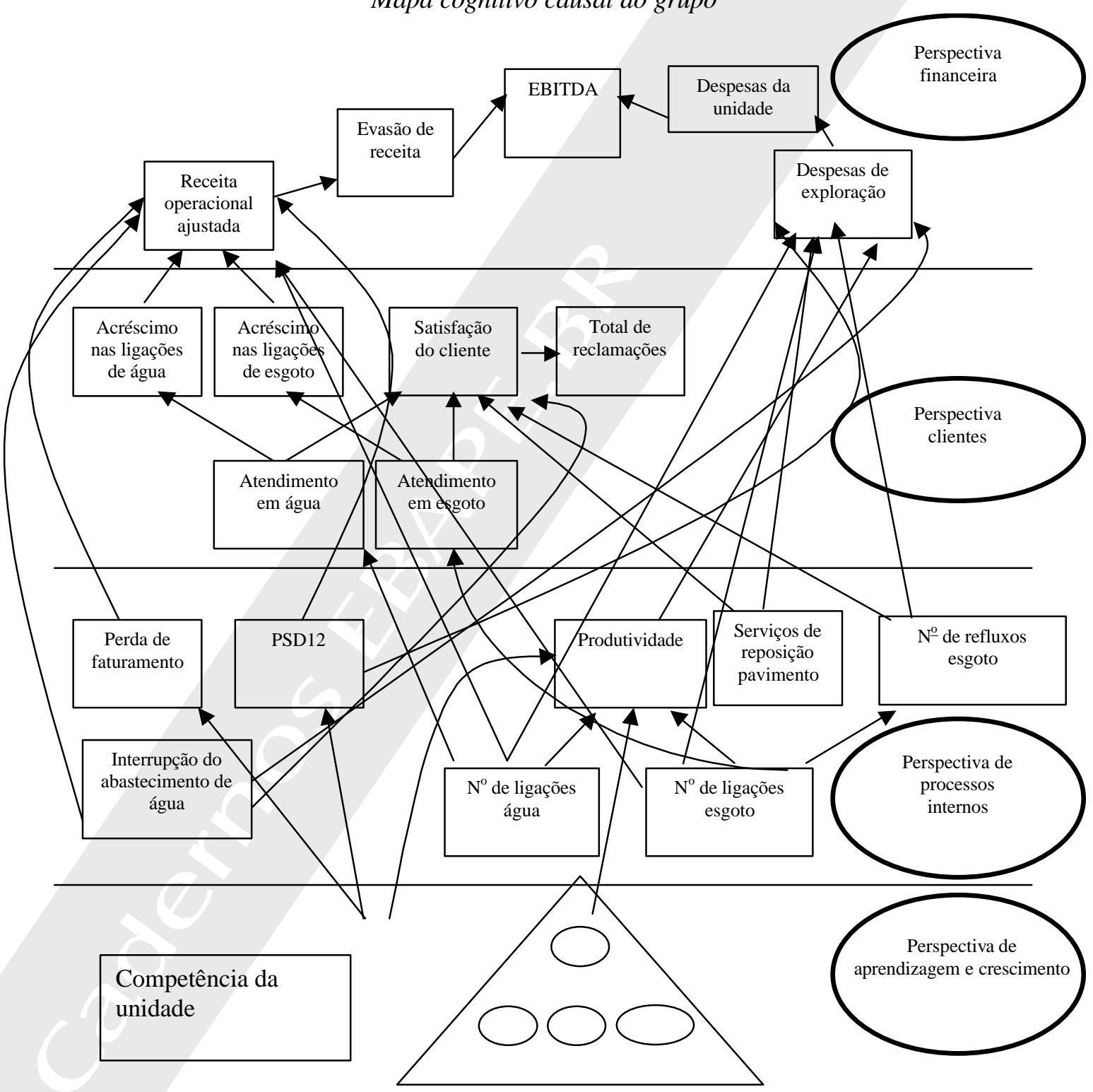

Fonte: autor e entrevistas. 


\section{Aplicação de técnicas de análise fatorial para simplificar os dados}

O modelo proposto pelo grupo revelou-se demasiadamente complexo para ser submetido a testes estatísticos. Assim, o passo seguinte foi aplicar a técnica estatística de análise fatorial, a fim de obter, para cada perspectiva do BSC qual fator explicaria a maior parte da variância. A tabela 1 apresenta os resultados.

\section{Tabela 1}

Síntese das variáveis do modelo após análise fatorial

\begin{tabular}{|c|c|c|c|c|c|}
\hline Perspectiva & $\begin{array}{l}\text { Variação } \\
\text { inicial }\end{array}$ & $\begin{array}{l}\text { Componentes/ } \\
\text { variáveis reduzidas }\end{array}$ & $\begin{array}{l}\text { Variância } \\
\text { explicada }\end{array}$ & Aceitação & Observação \\
\hline \multirow[b]{2}{*}{ Financeira } & \multirow{2}{*}{ 然 } & Receitas e despesas & 65,2 & Sim & Fator escolhido \\
\hline & & $\begin{array}{l}\text { Indicadores financeiros } \\
\text { líquidos }\end{array}$ & 22,6 & Sim & \\
\hline Clientes & 2 & Satisfação dos clientes & 67,9 & Não & $\begin{array}{l}\text { KMO }<0,7 \\
\text { Uso: variável satisfação } \\
\text { dos clientes }\end{array}$ \\
\hline \multirow{6}{*}{$\begin{array}{l}\text { Processos } \\
\text { internos }\end{array}$} & \multirow{2}{*}{6} & Metas - água & 60,0 & Sim & Fator escolhido \\
\hline & & Metas - esgoto & 24,0 & Sim & \\
\hline & \multirow{3}{*}{6} & Perdas no sistema & 48,2 & Não & \multirow{3}{*}{$\mathrm{KMO}<0,7$} \\
\hline & & Reparos e consertos & 21,3 & Não & \\
\hline & & $\begin{array}{l}\text { Interrupções no } \\
\text { abastecimento de água }\end{array}$ & 17,7 & Não & \\
\hline & 7 & Volume de recursos & 55,9 & Sim & Fator escolhido \\
\hline \multirow[t]{2}{*}{$\begin{array}{l}\text { Aprendizado/ } \\
\text { crescimento }\end{array}$} & & $\begin{array}{l}\text { Satisfação do } \\
\text { empregado }\end{array}$ & 20,9 & Sim & Fator escolhido \\
\hline & 9 & Entrega (competência) & 62,8 & Sim & Fator escolhido \\
\hline
\end{tabular}

Fonte: autor.

Duas variáveis de controle foram adicionadas posteriormente: realização das previsões de consumo e desempenho dos fornecedores. A primeira variável foi incluída porque o modelo assume que previsões realizadas durante o planejamento irão acontecer. Se não se efetivam, a performance pode ser fortemente afetada por motivo não relacionado a recursos ou competência. A segunda variável visou controlar até que ponto o fornecedor afeta o resultado da UN. Um novo mapa causal foi desenhado com as novas variáveis reduzidas e variáveis de controle. A figura 3 ilustra o resultado. 
Figura 3

Mapa causal com variáveis reduzidas

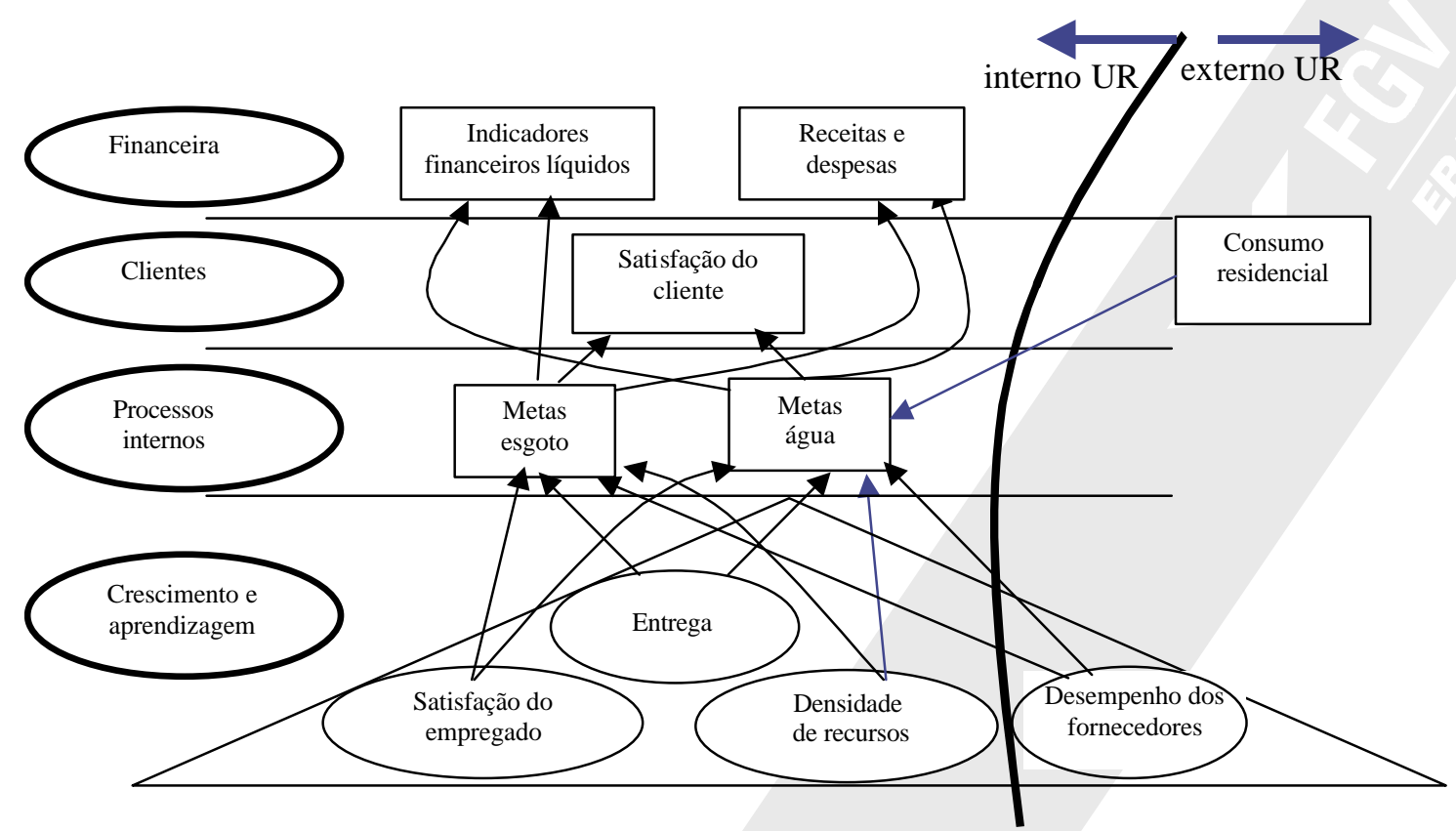

Fonte: autor.

Para resumir, o modelo propõe que as variáveis da base afetam as metas relativas ao fornecimento de água. Tais metas, se alcançadas, influenciarão a satisfação do consumidor e permitirão que as metas de faturamento e despesas sejam atingidas.

\section{Análises de regressão}

Uma análise de regressão foi conduzida para testar tais relações, examinando pares de variáveis (V.) quando a associação entre uma e outra tinham significado teórico. A tabela 2 ilustra os resultados.

\section{Tabela 2}

Análise de regressão das relações no modelo

\begin{tabular}{lcccc}
\hline $\begin{array}{l}\text { V. independente } \\
\text { V. dependente }\end{array}$ & Metas de & $\begin{array}{c}\text { Satisfação dos } \\
\text { água }\end{array}$ & $\begin{array}{c}\text { Receitas e } \\
\text { despesas }\end{array}$ \\
\hline $\begin{array}{l}\text { Satisfação dos } \\
\text { empregados }\end{array}$ & $R_{\text {ajustado }}^{2}$ & 0,405 & 0,227 & 0,090 \\
\hline \multirow{2}{*}{ Entrega } & Valor -p & 0,000 & 0,001 & 0,037 \\
\hline $\begin{array}{l}\text { Densidade de } \\
\text { recursos }\end{array}$ & $R_{\text {ajustado }}^{2}$ & $-0,017$ & $-0,014$ & $-0,027$ \\
\hline $\begin{array}{l}\text { Valor -p } \\
\text { Desempenho dos } \\
\text { fornecedores }\end{array}$ & $R_{\text {ajustado }}^{2}$ & 0,538 & 0,492 & 0,907 \\
\hline $\begin{array}{l}\text { Consumo } \\
\text { residencial }\end{array}$ & $R_{\text {ajustado }}^{2}$ & 0,110 & $-0,015$ & 0,104 \\
\hline $\begin{array}{l}\text { Metas de } \\
\text { água }\end{array}$ & $R_{\text {ajustodo }}^{2}$ & 0,023 & 0,510 & 0,027 \\
\hline
\end{tabular}


Os resultados mostram associações significativas entre o recurso "satisfação do empregado" e as três perspectivas da performance $(\mathrm{p}<0,05)$. A densidade de recursos revelou-se associada com a perspectiva de processos internos e as metas financeiras, mas não com a perspectiva dos clientes. As previsões de consumo residencial revelaram o efeito mais forte sobre os processos internos e as metas financeiras. As competências dos empregados e o desempenho dos fornecedores não demonstraram associação com a performance da UN.

\section{Modelagem de equações estruturais (structural equation modeling - SEM) para ajustar o mapa causal com melhor poder explicativo do modelo.}

Observadas as associações entre variáveis, optou-se por testar a sequiência causal proposta na figura 3 com o uso do SEM, implementada mediante o software Amos. Apesar de algumas variáveis independentes demonstrarem forte associação com todas as dependentes - por exemplo, a variável independente satisfação dos empregados - e outras demonstrarem fraca relação (desempenho dos fornecedores), optou-se por mantê-las todas no modelo a ser testado mediante SEM, uma vez que podem existir associações indiretas que a análise de regressão não é capaz de diagnosticar.

Hair (1998, p.583) sugere sete etapas para a aplicação do SEM:

- desenvolvimento do modelo teórico;

- construção de diagrama de caminho;

- conversão de diagrama de caminho em equações estruturais;

- escolha do tipo de matriz e estimativa do modelo proposto;

- avaliação da identificação do modelo estrutural;

- avaliação de critérios de adequação de ajuste; e

- interpretação e modificação do modelo.

A essa altura, as duas primeiras etapas já estavam cumpridas - desenvolver um modelo teórico e representar o path diagram. A terceira etapa na aplicação do SEM prevê a transcrição das equações estruturais. A tabela 3 apresenta os coeficientes a serem estimados.

Tabela 3

Coeficientes estimados no modelo - SEM

\begin{tabular}{|c|c|c|c|c|c|c|c|c|}
\hline \multirow[t]{2}{*}{ Variáveis endógenas } & \multicolumn{5}{|c|}{ Exógenas } & \multicolumn{3}{|c|}{ Endógenas } \\
\hline & Sat_e & Entrg & Den_r & D_for & Con_r & Met_a & Sat_c & Rec_d \\
\hline Met_a & $\mathrm{B}_{1}$ & $\mathrm{~B}_{2}$ & $\mathrm{~B}_{3}$ & $\mathrm{~B}_{4}$ & $\mathrm{~B}_{5}$ & & & \\
\hline Sat_c & 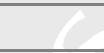 & & & & & $\mathrm{B}_{6}$ & & \\
\hline Rec_d & $\bar{C}$ & & & & & $\mathrm{~B}_{7}$ & & \\
\hline
\end{tabular}

Fonte: autor.

Na quarta etapa de aplicação do SEM, optou-se por utilizar variáveis padronizadas no modelo, a fim de se facilitar a análise dos resultados e propiciar melhor entendimento dos padrões de relacionamento entre as variáveis.

Para a quinta etapa, na primeira "parametrização" do modelo, admitiu-se um componente de erro para cada variável endógena, bem como a livre correlação entre os erros e entre as variáveis exógenas. A seguir, rodou-se o programa Amos, recurso specification search, para identificação das correlações mais expressivas. O recurso permite investigar quais relações são necessárias para melhor interpretação do modelo. As correlações mais significativas foram incorporadas a este e procedeu-se ao cálculo das estimativas. A tabela 4 indica os resultados. 
Tabela 4

Coeficientes de regressão - modelo inicial

\begin{tabular}{lccccc}
\hline Variáveis & Estimativa & S.E. & C.R. & P & Coeficientes padronizados \\
\hline Met_a <-- Con_r & 0,637 & 0,111 & 5,728 & $* * *$ & 0,594 \\
\hline Met_a <-- Entrg & $-0,081$ & 0,089 & $-0,905$ & 0,365 & $-0,081$ \\
\hline Met_a <-- Sat_e & 0,391 & 0,109 & 3,607 & $* * *$ & 0,374 \\
\hline Met_a <-- Den_r & 0,238 & 0,089 & 2,678 & 0,007 & 0,238 \\
\hline Met_a <-- D_for & 0,112 & 0,108 & 1,034 & 0,301 & 0,102 \\
\hline Rec_d<-- Met_a & 0,600 & 0,143 & 4,189 & $* * *$ & 0,669 \\
\hline Sat_c <-- Met_a & 0,832 & 0,187 & 4,449 & $* * *$ & 0,801 \\
\hline *** valor-P<0,001 & & & & & \\
Fonte: Amos. & & & & &
\end{tabular}

Os resultados demonstram que, dos coeficientes estimados no modelo, quatro revelaram significância, dois entre variáveis exógenas (consumo residencial e satisfação dos empregados) e as metas de água. Ao mesmo tempo, atingir as metas de água parece associado ao alcance de metas em termos de receitas e despesas e também de satisfação do cliente. A relação entre densidade de recursos e metas de água aparece com valor-p igual a 0,007 . Porém, entrega e desempenho do fornecedor parecem absolutamente dissociados do alcance das metas de água.

Ao se observar os coeficientes de regressão padronizados, nota-se que, dos fatores que influenciam a consecução das metas de água, a realização das previsões de consumo residencial aparecem com maior força; em seguida, vem a satisfação do empregado e, em terceiro, a densidade de recursos. Quando se desvia a atenção para as perspectivas de clientes e financeira, o alcance das metas operacionais parece contribuir em ambos os casos.

A sexta etapa na aplicação do SEM diz respeito à avaliação do ajuste do modelo. Porém, avaliar o nível de ajuste do SEM não é tão direto como em outras técnicas multivariadas de dependência. "SEM não possui um teste estatístico particular que melhor descreva a força das previsões do modelo" (HAIR et al., 1998, p.653). Harlow e Curran (2003) propõem quatro categorias de análise:

- critério qualitativo/teórico, considerando uma boa adequação à teoria e a parcimônia do modelo (isto é, o modelo tem poucos parâmetros);

- critérios quantitativos/empíricos, como ajuste geral, ajuste específico e ajuste de parcimônia;

- comparação de modelos; e

- validação cruzada.

Hair (1998, p.653) organiza esse conjunto de medidas sob três ângulos: ajuste geral ou ajuste absoluto; ajuste incremental comparativo a um modelo base e ajuste de parcimônia. Este último tenta maximizar o grau de ajuste por coeficiente estimado, evitando "sobreajustar" o modelo com coeficientes adicionais que agregam pequenos ganhos ao ajuste, semelhante ao $\mathrm{R}^{2}$ na regressão múltipla. ${ }^{5}$ No entanto, "nenhum teste absoluto está disponível, e o pesquisador deve, no final, decidir se o ajuste é ou não aceitável" (HAIR et al., 1998, p.653). Nesta pesquisa, seguindo outros autores (CONTI et al., 2003), optou-se por avaliar uma medida dentro de cada ângulo. O quadro 3 mostra e explica as medidas escolhidas.

\footnotetext{
${ }^{5}$ Porém, como não há teste estatístico disponível para essas medidas, em muitos casos, seu uso em sentido absoluto é limitado a comparações com outros modelos" (HAIR et al., 1998, p.658).
} 
Quadro 3

Medidas escolhidas para avaliação do ajuste do SEM

\begin{tabular}{ll}
\hline Medida de ajuste & NIVEIS DE ACEITAÇÃO DO AJUSTE \\
\hline Medidas de ajuste absoluto & \\
\hline $\begin{array}{l}\text { Root mean square error of approximation } \\
\text { (RMSEA) }\end{array}$ & $\begin{array}{l}\text { Média da diferença por graus de liberdade esperados } \\
\text { para ocorrer na população, não na amostra. Aceitáveis } \\
\text { valores abaixo de 0,08 }\end{array}$ \\
\hline Medidas de ajuste incremental & \\
\hline Tucker-Lewis Index (TLI) & "Distância" no caminho entre o modelo independente \\
(ou modelo base, de pior ajuste) e o modelo saturado, & de ajuste perfeito. \\
& Sem valores absolutos para ajuste aceitável. \\
& Recomendável acima de 0,90 \\
\hline Parcimônia do modelo & Ajuste do Chi-quadrado aos graus de liberdade. \\
\hline Normed chi-square & Recomendável: \\
& Limite inferior: 1,0 \\
Limite superior: $2,0 / 3,0$ ou 5,0
\end{tabular}

Fonte: Hair et al. (1998, p.660), Harlow e Curran (2003, p.8) e Bentler e Bonett (1980, p.600).

A tabela 5 apresenta alguns indicadores de ajuste do modelo inicial.

Tabela 5

Ajuste do modelo inicial

\begin{tabular}{lcc}
\hline Medida de ajuste & Cálculo da medida & Aceitação \\
\hline RMSEA & 0,02 & Aceitável \\
\hline TLI & 0,972 & Aceitável \\
\hline Normed chi-square & 1,015 & Aceitável \\
\hline \hline
\end{tabular}

Fonte: Amos.

Pela ótica das medidas escolhidas, o modelo parece aceitável.

A etapa seguinte consistiu em testar modelos alternativos, teoricamente justificáveis, que possuíssem melhor poder explicativo e melhores índices de ajuste. Assim, foi novamente consultado um profissional da empresa para que assinalasse relações causais possíveis e alternativas. A figura 4 apresenta em vermelho as relações do primeiro modelo, adicionadas a outras relações possíveis. As relações foram testadas na busca do melhor modelo. 


\section{Figura 4}

Relações alternativas de causalidade teoricamente consistentes

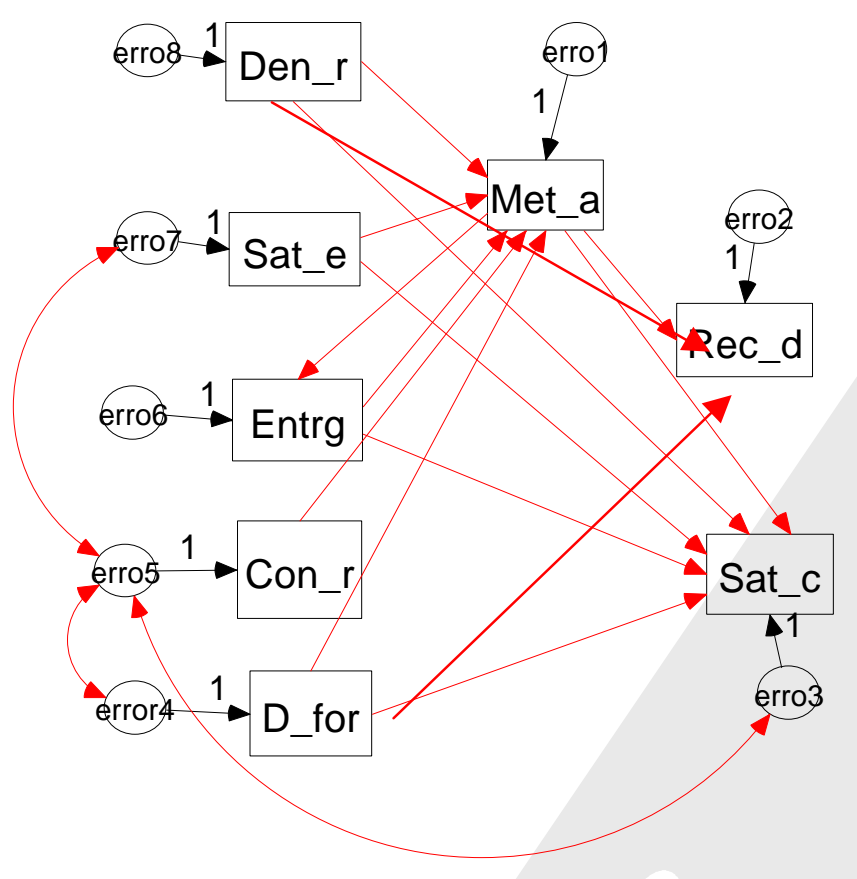

Fonte: Amos.

Além de testar novamente as relações do primeiro modelo em seu conjunto, o novo teste examinou:

- se a relação entre alcance das metas e entrega/competência não seria invertida: "não é um maior nível de competência que garante o alcance de resultados operacionais, mas é porque se alcançou tais resultados que se avalia a equipe como competente". 6

- se as variáveis densidade de recursos, satisfação dos empregados, entrega e desempenho do fornecedor influenciam diretamente a satisfação dos clientes;

- se as variáveis densidade de recursos e desempenho do fornecedor influenciam diretamente a perspectiva financeira.

$\mathrm{O}$ novo teste, segundo vários critérios, apontou o modelo da figura 5 como o de melhor ajuste e poder explicativo. A tabela 6 indica os resultados e a tabela 7, os índices de ajuste. A correlação entre os erros não se mostrou expressiva (valor-p mínimo igual a 0,026).

6 Essa relação invertida também poderia ser testada para a satisfação do empregado. Não o foi, porém, porque a pesquisa de clima que ocasionou 0 indicador aconteceu antes da geração dos resultados operacionais. Já a avaliação de competências e a divulgação dos resultados foram quase simultâneas. 


\section{Figura 5}

Modelo final - relações e coeficientes padronizados

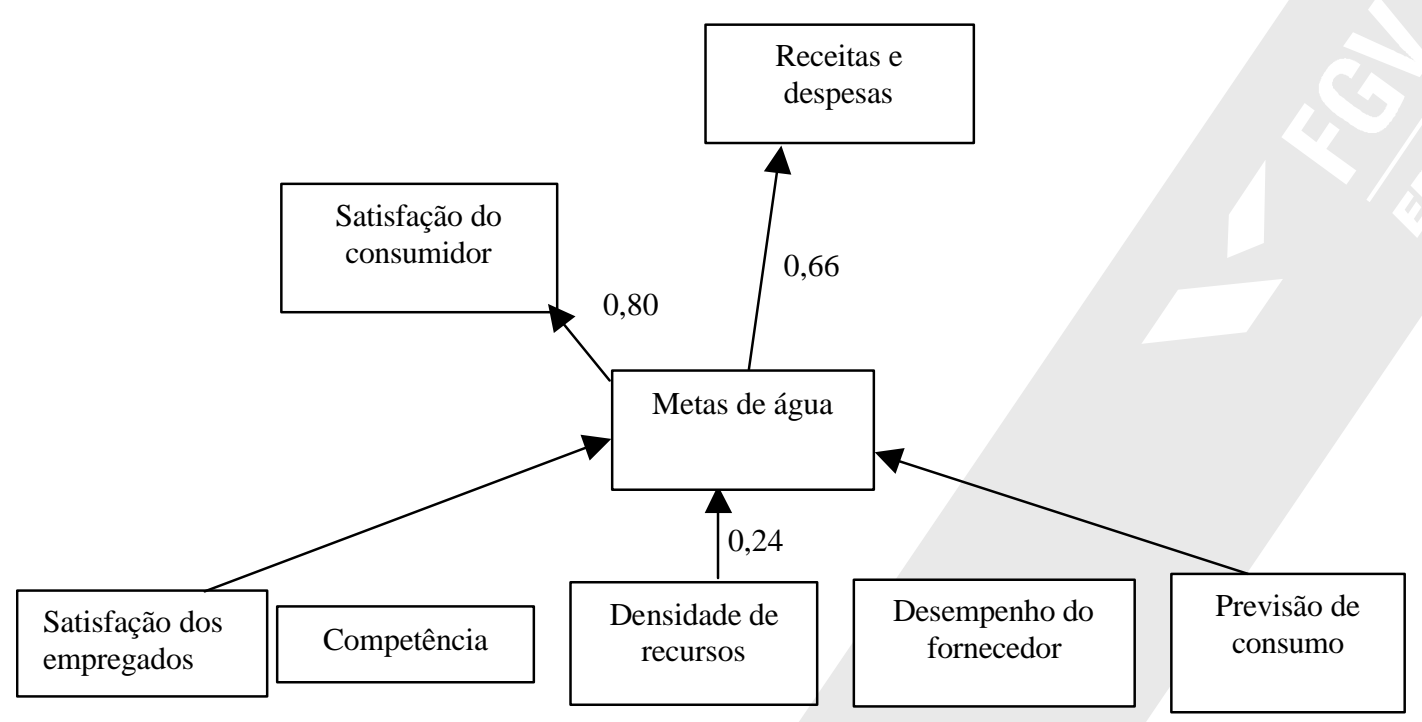

Fonte: adaptado de Amos.

Tabela 6

Coeficientes de regressão - modelo final

\begin{tabular}{llllll}
\hline Variáveis & Estimativa & S.E. & C.R. & P & Coeficientes padronizados \\
\hline Met_a <-- Con_r & 0,660 & 0,110 & 5,981 & $* * *$ & 0,598 \\
\hline Met_a <-- Sat_e & 0,434 & 0,106 & 4,091 & $* * *$ & 0,404 \\
\hline Met_a <-- Den_r & 0,243 & 0,089 & 2,730 & 0,006 & 0,236 \\
\hline Rec_d <-- Met_a & 0,568 & 0,139 & 4,079 & $* * *$ & 0,660 \\
\hline C_sat2 <-- Met_a & 0,795 & 0,181 & 4,402 & $* * *$ & 0,796
\end{tabular}

Fonte: Amos.

Tabela 7

Ajuste do modelo final

\begin{tabular}{lll}
\hline Medida de ajuste & Cálculo da medida & ACEITAÇÃO \\
\hline RMSEA & 0,000 & Aceitável \\
\hline TLI & 1,103 & Aceitável \\
\hline Normed chi-square & 0,944 & Marginal \\
\hline
\end{tabular}

Fonte: Amos.

O segundo modelo, embora com alguns indicadores inferiores ao primeiro, parece ser mais adequado: é mais parcimonioso, excluindo variáveis de fraca associação com as demais, como entrega e desempenho do fornecedor. Quatro relações causais são significativas para um valor-p menor que 0,001 :

- consumo residencial e alcance das metas de água;

- satisfação do empregado e metas de água;

- metas de água com receitas e despesas;

- metas de água com satisfação dos clientes.

$\mathrm{O}$ vínculo entre densidade de recursos e metas de água aparece com valor-p=0,006. 


\section{Conclusão}

Este artigo teve por objetivo propor uma metodologia para rastrear a sequiência de causalidade entre direcionadores e indicadores de performance dentro do mapa causal. De forma geral, a metodologia visa refinar as crenças de causa-e-efeito, de modo a aperfeiçoar o sistema de mensuração de performance de uma determinada organização.

A metodologia propõe o levantamento das principais variáveis relacionadas ao desempenho da organização. A massa de dados é então simplificada mediante técnicas de análise fatorial, e por meio de análises de regressão, algumas correlações são investigadas. A seguir, aplica-se o SEM para ver qual o formato das relações teria maior poder explicativo para as variáveis estudadas.

No caso dos dados da pesquisa, verificou-se que algumas variáveis supostamente causadoras de um bom desempenho organizacional revelaram-se inócuas: o nível de competência dos empregados e o desempenho dos fornecedores. Algumas particularidades da empresa analisada justificam o resultado. Por exemplo, as unidades investigadas eram de nível extremamente operacional, com tarefas de baixa complexidade. Talvez em negócios de maior capital intelectual o resultado seja diferente. Ainda, a competência aparece na performance de médio/longo prazo, quando o horizonte deste estudo foi de um ano. Com relação aos fornecedores, uma possível explicação para a ausência de impacto é o nível de atendimento relativamente uniforme da performance dos fornecedores na amostra.

Outras variáveis revelaram influência sobre a performance. Uma delas foi a motivação dos funcionários, que demonstrou estar ligada ao fato de se atingir as metas operacionais e, por meio destas metas, propiciar maior satisfação dos clientes e o alcance das metas financeiras. Aqui o SEM revelou dados interessantes. Por exemplo, que o impacto da satisfação dos funcionários sobre a satisfação dos clientes é melhor explicado indiretamente do que diretamente - o que é compreensível nesse negócio, onde a interação entre funcionários e clientes tende a ser mais remota que em outros setores, como hotelaria ou lojas de departamento. Assim, a satisfação dos empregados se converteu em satisfação dos clientes quando a moral alta dos funcionários foi direcionada para a realização das metas operacionais. A relação indireta é coerente com o proposto pelo mapa causal.

A metodologia apresenta limitações. A primeira é a de que as condições exigidas para o teste são bastante restritivas: existência de unidades organizacionais comparáveis e em número suficiente para suportar a técnica estatística, mensuradas pelos mesmos indicadores de performance, e algum controle de variáveis espúrias que possam afetar fortemente o desempenho. Inclusive, neste caso, a necessidade de buscar unidades comparáveis acabou por limitar o estudo a uma só empresa, bem como a unidades de negócio de mesma natureza.

A rigor, a amostra utilizada neste estudo é insuficiente (38 casos). Para minimizar qualquer viés, utilizou-se um algoritmo de cálculo mais robusto e menos sensível à não normalidade (mínimos quadrados generalizados ou generalized least squares - GLS). Entretanto, como a preocupação deste artigo é ilustrar o uso da técnica, e não tanto os resultados em si, a questão da amostra acaba por ficar em segundo plano. Nesse sentido, as conclusões do estudo exemplificam as possibilidades de análise. Assim, uma das recomendações para pesquisa futura é a da aplicação da técnica em uma amostra mais ampla.

Este estudo também revelou uma lacuna nas pesquisas empíricas quantitativas acerca das causas da performance organizacional, ao mesmo tempo em que sugere uma situação particular e uma técnica de análise que pode render bons frutos quando aplicada a tais questões. 


\section{Referências bibliográficas}

AMOS 4 User's guide. Tutorial: get running with Amos Graphics. Disponível em: $<$ www.smallwaters.com/amos/student.html $>$. Acesso em: 15-8-2003.

BARBER, L; HAYDAY, S.; BEVAN, S. From people to profits. Brighton: The Institute for Employment Studies. (Report 355, 1999).

BECKER, B. E.; GERHART, B. The impact of human resources management on organizational performance: progress and prospects. Academy of Management Journal, Briarcliff Manor-NY, v.39. n.4, p.779-801, 1996.

BENTER, P. M.; BONETT, D. G. Significance tests and goodness of fit in the analysis of covariance structures. Psychological Bulletin, v.88, p.588-606, 1980.

CONTI, R et al. The effects of just- in- time/lean production practices on worker job stress. Institute for Manufacturing. Cambridge: University of Cambridge, 2003. (Working paper)

DUTRA, J. S. Gestão de pessoas com base em competências. In: DUTRA, J. S. (Org.). Gestão por competências: um modelo avançado para 0 gerenciamento de pessoas. São Paulo: Ed. Gente, 2001. p.23-40.

EPSTEIN, M.; MANZONI, J. F. Implementing corporate strategy: from tableaux de bord to balance scorecards. European Management Journal, Oxford, v.16, n.2, p.190-203, 1998.

FARIAS, G.; VARMA, A. A High Performance Work Systems: What We Know and What We Need to Know. Human Resource Planning. New York NY, v. 21, n. 2, p. 50-55, 1998.

FLEURY, A.; FLEURY, M. T. L. Estratégias empresariais e formação de competências: um quebra cabeça caleidoscópico da indústria brasileira. 2.ed. São Paulo: Atlas, 2001.

HAIR, J. et al. Multivariate data analysis. 5.ed. Englewood Cliffs-NJ, 1998.

HARLOW, L. L.; CURRAN, J. M. Structural equation modeling. In: Workshop - Bryant College, Boston, EUA, em 16-1-2003.

HESKETT, J.; SASSER, W.; SCHLESINGER, L. The service profit chain: how leading companies link profit and growth to loyalty, satisfaction and value. New York: The Free Press, 1997.

HUFF, Anne S. Mapping Strategic Thought. In HUFF, Anne S. (ed). Mapping Strategic Thought. Chichester: Wiley and Sons, 1990.

KAPLAN, R.; NORTON, D. The balanced scorecard - measures that drive performance. Harvard Business Review, Boston, v.70, n.1, p.71- 79, Jan./Feb. 1992.

-_-_-_; -_-_-_. The balanced scorecard: translating strategy into action. Boston: Harvard Business School Press, 1996.

MILLS, J. F.; ROCHA- FERNANDES, B. H.. Linking resources and organizational performance: replicated research designs, a case and a warning. Edinburgo: Anais do Performance Measurement Association Conference, Julho 2004, p. 715- 722.

NEELY, A.; NAJJAR, M. Linking financial performance to employee and customer satisfaction. In: NEELY, A. (Ed.). Business performance measurement: theory and practice. Cambridge: Cambridge University Press, 2003. p.295-303.

PENROSE, E. T. The theory of growth of the firm. London: Basil Blackwell, 1959.

ROCHA-FERNANDES, B. H. Competências e performance organizacional: um estudo empírico. Tese (Doutorado) - Faculdade de Economia e Administração, Universidade de São Paulo. 2004.

RUCCI, A. J.; KIM, S. P.; QUINN, R. T. The employee-customer-profit chain at Sears. Harvard Business Review, Boston, v.76, n.1, p.83-97, Jan./Feb. 1998.

SANARE - Revista Técnica da Sanepar. Curitiba, v.18, n.18, jul./dez. 2002. Disponível em: «www.sanepar.com.br/publicações/sanare/>. Acesso em: 17-10-2003. 